\title{
Changing and Differentiated Urban Landscape in China: Spatiotemporal Patterns and Driving Forces
}

\author{
Chuanglin Fang, ${ }^{\dagger}$ Guangdong $\mathrm{Li}^{*}{ }^{\dagger}{ }^{\dagger}$ and Shaojian Wang ${ }^{*,+}$
}

${ }^{\dagger}$ Key Laboratory of Regional Sustainable Development Modeling, Institute of Geographic Sciences and Natural Resources Research (IGSNRR), Chinese Academy of Sciences (CAS), 11A Datun Road, Chaoyang District, Beijing 100101, China

${ }^{\ddagger}$ Guangdong Provincial Key Laboratory of Urbanization and Geo-simulation, School of Geography and Planning, Sun Yat-sen University, Guangzhou 510275, China

\section{Supporting Information}

ABSTRACT: Urban landscape spatiotemporal change patterns and their driving mechanisms in China are poorly understood at the national level. Here we used remote sensing data, landscape metrics, and a spatial econometric model to characterize the spatiotemporal patterns of urban landscape change and investigate its driving forces in China between 1990 and 2005. The results showed that the urban landscape pattern has experienced drastic changes over the past 15 years. Total urban area has expanded approximately 1.61 times, with a $2.98 \%$ annual urban-growth rate. Compared to previous single-city studies, although urban areas are expanding rapidly, the overall fragmentation of the urban landscape is decreasing and is more irregular and complex at the national level. We also found a stair-stepping, urban-landscape changing pattern among eastern, central, and western counties. In addition, administrative level, urban size, and hierarchy have effects on the urban landscape pattern. We also found that a combination of landscape metrics can be used to supplement our understanding of the pattern of urbanization. The changes in these metrics are correlated with geographical indicators, socioeconomic factors, infrastructure variables, administrative level factors, policy factors, and historical factors. Our results indicate that the top priority should be strengthening the management of urban planning. A compact and congregate urban landscape may be a good choice of pattern for urban development in China.

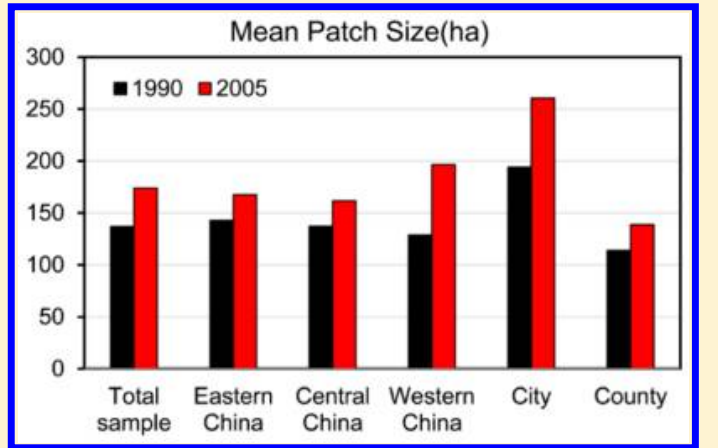

\section{INTRODUCTION}

Over the past several decades, urbanization and urban landscape change have been the most dramatic changes to affect the earth's surface. ${ }^{1-3}$ Globally, more people live in urban areas than in rural areas: $54 \%$ of the world's population lived in urban areas in $2014,{ }^{4}$ compared to a mere $10 \%$ in $1900 .^{2}$ The unprecedented rates of urban population growth over the past century have also driven rapid urban land expansions on a worldwide scale because of changes made to land to build cities and support the demands of urban populations. ${ }^{5-8}$ Urban areas are the centers of economic and population agglomerations, social services, culture, and politics. Although they are the engine of society's innovation and prosperity, ${ }^{9,10}$ they are also the main cause of serious environmental problems such as air pollution, ${ }^{11-13}$ water pollution, ${ }^{14}$ increased anthropogenic greenhouse gas emissions, ${ }^{15}$ urban heat islands, ${ }^{16,17}$ and reduced biodiversity. ${ }^{18}$ Urban areas both pose problems and provide solutions related to human societies' sustainable future. ${ }^{2}$ Therefore, the spatial and temporal characteristics, causes, and consequences of urban landscape changes must be scientifically understood before cities can be put on a sustainable development path.

According to the projection of World Urbanization Prospects 2014, most urban growth will occur in developing countries, and the scale of urbanization will be most extraordinary in China. ${ }^{4}$ With its unprecedented economic growth, China has been witnessing a dramatic increase in urbanization since the 1978 implementation of economic reforms. ${ }^{19}$ In 1978, 17.92\% of Chinese were urban dwellers. By 2014, this proportion had increased to $54.77 \% .{ }^{20}$ Meanwhile, China's urban landscape and land use patterns have changed profoundly. Urban areas in China have increased exponentially, by more than 4 times (from $9775 \mathrm{~km}^{2}$ to $45566 \mathrm{~km}^{2}$ ) between 1985 and 2012. ${ }^{21,22}$ Within this broad context, China's rapid urbanization and urban landscape changes in recent decades have provided a good laboratory to deepen and extend our understanding of the spatiotemporal patterns and driving mechanisms of the changing urban landscape. ${ }^{9,23}$

Landscape metrics can be defined as quantitative indices that describe the structures and patterns of a landscape. ${ }^{24,25}$ They can be used both to monitor urban landscape changes ${ }^{1}$ and to direct policy makers to make appropriate decisions about sustainable development. ${ }^{26}$ Recently there has been an

Received: October 27, 2015

Revised: February 6, 2016

Accepted: February 8, 2016

Published: February 8, 2016 
Table 1. Landscape Metrics of Urban Landscape Analysis Used in the Study

\begin{tabular}{|c|c|c|c|}
\hline $\begin{array}{l}\text { landscape } \\
\text { metrics }\end{array}$ & abbreviation & formula & description \\
\hline total urban area & CA & $\mathrm{CA}=\sum_{j=1}^{n} a_{j}(1 / 10000)$ & $a_{j}=$ area $\left(\mathrm{m}^{2}\right)$ of urban patch $j$ \\
\hline $\begin{array}{c}\text { number of } \\
\text { patches }\end{array}$ & NP & $\mathrm{NumP}=n$ & $n=$ number of urban patches \\
\hline mean patch size & MPS & MPS $=\frac{\sum_{j=1}^{n} a_{j}}{n}$ & $a_{j}=$ area $\left(\mathrm{m}^{2}\right)$ of urban patch $j, n=$ number of urban patches \\
\hline edge density & ED & $\mathrm{ED}=(10000) \sum_{j=1}^{n} e_{j} / \mathrm{AREA}$ & $\begin{array}{l}e_{j}=\text { total length }(\mathrm{m}) \text { of edge in landscape involving urban patch } j \text {, including landscape boundary } \\
\text { and background segments of urban patch, AREA }=\text { total landscape area }\left(\mathrm{m}^{2}\right)\end{array}$ \\
\hline $\begin{array}{l}\text { mean shape } \\
\text { index }\end{array}$ & MSI & $\mathrm{MSI}=\frac{\sum_{j=1}^{n} \frac{p_{j}}{2 \sqrt{\pi a_{j}}}}{n}$ & $p_{j}=$ perimeter of urban patch $j, a_{j}=$ area of urban patch $j, n=$ number of urban patches \\
\hline $\begin{array}{l}\text { area weighted } \\
\text { mean patch } \\
\text { fractal } \\
\text { dimension }\end{array}$ & AWMPFD & AWMPFD $=\sum_{i=1}^{m} \sum_{j=1}^{n}\left(\frac{2 \ln \left(0.25 p_{i j}\right)}{\ln a_{i j}} \frac{a_{i j}}{A}\right)$ & $\begin{array}{l}m=\text { the number of patch types; } n=\text { the number of patch of a class; } p_{i j}=\text { the perimeter of patch } i j ; \\
a_{i j}=\text { the area of patch } i j ; A=\text { total landscape area }\end{array}$ \\
\hline $\begin{array}{l}\text { annual rate of } \\
\text { urban area } \\
\text { growth }\end{array}$ & AUG & $\mathrm{AUG}=\left(\left(A_{\text {end }} / A_{\text {start }}\right)^{1 / d}-1\right) \times 100$ & $\begin{array}{l}\text { AUG is the annual rate of urban land expansion; } A_{\text {end }} \text { and } A_{\text {start }} \text { are the extent of the urban land } \\
\text { area at the start and end time of period, respectively; } d \text { is the time span of the study in years }\end{array}$ \\
\hline $\begin{array}{l}\text { urbanization } \\
\text { intensity index }\end{array}$ & UII & $\mathrm{UII}_{i}=\left(\frac{\mathrm{UA}_{i \mathrm{~L}}-\mathrm{UA}_{i \mathrm{~F}}}{\mathrm{TA}_{i}}\right) \times \frac{1}{N} \times 100$ & $\begin{array}{l}\mathrm{UII}_{i} \text { means the index of urbanization intensity for each unit } i ; \mathrm{UA}_{i \mathrm{~L}} \text { and } \mathrm{UA}_{i \mathrm{~F}} \text { represents the total } \\
\text { urban area of unit } i \text { in the last year and the first year of our study period, respectively; } \mathrm{TA}_{i} \text { is the } \\
\text { total area of unit } i \text { and } \mathrm{N} \text { stands for the length of the study period }\end{array}$ \\
\hline
\end{tabular}

increasing interest in applying landscape metrics supported by remote sensing (RS) and geographic information systems (GIS) to urban landscape changes to monitor, model, and assess the dynamics of urban landscape patterns and growth processes. ${ }^{3,5,27-37}$ However, most previous studies have been conducted either at the single city level ${ }^{26,38-40}$ or at the metropolitan level. ${ }^{34,41}$ Overall, research on urban landscape change in a national or global context is lacking ${ }^{42}$ and it is difficult to scale up single-city case studies to regional and national levels. Currently, we do not know the overall patterns and regional differences of urban landscape change in China at the national level. Additionally, the impact of administrative level on urban landscape change remains unexplained. In two recent insightful interviews, two experts called for more indepth studies on urbanization in China at the national level, and greater theoretical understanding. ${ }^{43,44}$

Characterizing the urban form itself, however, is insufficient to advance our understanding of urban landscape patterns. ${ }^{28}$ Identification of the driving forces of urban landscape change are the most urgent and fundamental issues in urban landscape analysis. It is widely recognized that the change in urban landscape is strongly influenced by socioeconomic, geophysical, and institutional constraints ${ }^{42,45-47}$ and that demography and economics are the most important driving factors. ${ }^{48,49}$ Moreover, proximity variables, topological variables, neighborhood factors, and policy variables are considered important factors affecting urban land use changes. ${ }^{28,46,50}$ That notwithstanding, the determinants of urban landscape change have previously only been analyzed for single cities, not than a national scale, except for a few insightful studies. ${ }^{49,51}$ However, it is difficult to generalize the driving forces of urban landscape change of individual cities to other regions. Moreover, driving mechanism analyses of urban expansion (or urban sprawl) generally represent the dominant direction of research. ${ }^{51-56}$ That said, urban landscape change is more comprehensive than urban expansion. In analytical methods, spatial autocorrelation among spatial units has seldom been considered in determinant studies of urban landscape change. ${ }^{4,57}$ However, ignoring spatial effects might lead to biased results because spatial effects are important in geographic processes. ${ }^{58}$

In this study, we first performed a national-scale urban landscape change analysis based on landscape metrics to characterize the spatiotemporal dynamics of urban landscape pattern changes in China. Second, we conducted a regional difference analysis of urban landscape pattern changes to understand the degree and magnitude of differences among regions and between cities and counties. Third, we quantified the driving forces of changes in urban landscape at the county level, considering geographical, socioeconomic, infrastructure, administrative level, policy, and historical factors. We end with a brief discussion of the policy implications of our results.

\section{MATERIALS AND METHODS}

Urban Land Use Data Set. We used two periods of land use data (1990 and 2005) developed by the Institute of Geographical Sciences and Natural Resources Research (IGSNRR, http://www.igsnrr.ac.cn) of the Chinese Academy of Sciences (CAS) from Landsat TM and Landsat ETM scenes with a spatial resolution of $30 \mathrm{~m} \times 30 \mathrm{~m}$. To build a nationalscale land use data set, 514 Landsat TM scenes from 1987 to 1990 and 411 Landsat ETM images and CCD images from CBERS-2 as a supplement in the uncovered area in 2004/2005 were chosen and radiantly corrected in a remote sensing satellite ground receiving station, CAS. ${ }^{59,60}$ Detailed procedures for deriving the extent of an urban area can be found in previous works. $^{60,61}$ According to field validation, the average interpretation accuracy was $92.9 \%$ for 1990 and more than $95 \%$ for 2005. ${ }^{59,60}$ Figure S1 shows a national-scale spatial distribution of urban land use changes, especially in the Beijing-Tianjin region, Yangtze River Delta and Pearl River Delta (see Supporting Information (SI), Figure S1).

Landscape Metrics. To understand the use frequency of landscape metrics in urban landscape pattern analysis, we reviewed more than 100 published papers from Web of Science (2002-2014) and chose 20 for detailed summary analysis (SI, Table S1). In this study, we selected the six most frequently 
Table 2. Selected Variables Influencing Urban Landscape Pattern Change

\begin{tabular}{|c|c|c|c|}
\hline variable category & $\begin{array}{l}\text { variable } \\
\text { name }\end{array}$ & description & sources \\
\hline \multirow[t]{2}{*}{$\begin{array}{l}\text { geographical } \\
\text { factors }\end{array}$} & LNAREA & $\begin{array}{l}\text { administrative area of each county (natural } \\
\text { logarithm) }\end{array}$ & \multirow[t]{2}{*}{ computed by ArcGIS 10.2} \\
\hline & REGION & $\begin{array}{l}\text { regional dummy variable (1,2,3 represent the } \\
\text { western, central, and eastern regions, respectively) }\end{array}$ & \\
\hline \multirow{4}{*}{$\begin{array}{l}\text { socioeconomic } \\
\text { factors }\end{array}$} & LNPOP & population of each county (natural logarithm) & \multirow{4}{*}{$\begin{array}{l}\text { socioeconomic statistical yearbook for China's counties }(1992,2006) \text {, regional } \\
\text { economy statistical yearbook of China (2006), urban statistical yearbook of China } \\
(1992,2006) \text {, and provincial statistical yearbook }(1992,2006)\end{array}$} \\
\hline & URBAN & urbanization level & \\
\hline & LNGDP & constant GDP per capita (natural logarithm) & \\
\hline & LNREV & local financial revenue per capita (natural logarithm) & \\
\hline $\begin{array}{l}\text { infrastructure } \\
\text { factor }\end{array}$ & LNROAD & $\begin{array}{l}\text { railway, highway and national road density (length/ } \\
\text { area, (natural logarithm)) }\end{array}$ & \multirow[t]{2}{*}{$\begin{array}{l}\text { Chinese Academy of sciences (CAS) Data Sharing Network of Earth System Science } \\
\text { (www.geodata.cn) }\end{array}$} \\
\hline $\begin{array}{l}\text { administrative } \\
\text { level factor }\end{array}$ & CITY & city and county dummy variable ( 1 or 0$)$ & \\
\hline policy factor & POLICY & $\begin{array}{l}\text { summary of preferential policy in China at the } \\
\text { county level (see the timeline of China's regional } \\
\text { preferential policies from } 1979 \text { to 2010) }\end{array}$ & $\begin{array}{l}\text { update and extend the study of Li and Fang }(2014) ;^{58} \text { the official web portal of the } \\
\text { Central People's Government of the People's Republic of China (http://english. } \\
\text { gov.cn/) }\end{array}$ \\
\hline historical factor & HISTORY & landscape metrics value of base year (1990) & landscape metrics computed by Patch Analyst 5.1 software \\
\hline
\end{tabular}

used landscape metrics based on summary analysis of the literature and two new quantitative indices (Table 1). Six indices as compositional measures were considered that describe four aspects of urban landscape: absolute size, relative size, edge metrics and complexity of urban form. ${ }^{3}$ Absolute size is characterized by two indices: total urban area (CA) and number of urban patches (NP). It is generally recognized that in urban growth, the total urban area continually increases. An NP metric is a measure of discrete urban areas in the landscape and is expected to increase during periods of rapid urban core growth; however, it may decrease if urban areas expand and merge into a continuous urban fabric. ${ }^{3}$ Relative size is described by the mean patch size (MPS). MPS is an effective indicator to characterize urban form changes, and a high MPS value is usually a signal meaning a more aggregated, less fragmented and contiguous urban landscape. Edge density (ED) measures the total edges of urban areas relative to the total landscape. Low ED value across the urban landscape corresponds to a high value of contiguity for that landscape. ${ }^{62}$ In practice, the MPS and ED have also been recommended as fragmentation metrics. ${ }^{63}$ The complexity of urban landscape is described by mean shape index (MSI) and the area-weighted mean patch fractal dimension (AWMPFD). The more irregular and complex the shape of the urban area, the higher the value of MSI and the fractal dimension. ${ }^{3}$ In addition, the annual rate of urban area growth (AUG) ${ }^{27}$ and urbanization intensity index $(\mathrm{UII})^{39}$ are used to investigate the change rate of urban landscape and urbanization intensity.

The software package for urban landscape pattern analysis, the Patch Analyst 5.1 software application for ESRI ArcGIS $10.2,{ }^{64}$ which is a derivative of the FRAGSTATS software program, ${ }^{62}$ was used to quantify the changes in China's urban landscape patterns. Landscape level analyses simply perform calculations for individual counties using Spatial Statistics (by regions), an embedded tool of the Patch Analyst 5.1 software. We calculated these landscape metrics for 1990 and 2005 for each county-level unit of China (2233 counties). We used the county-level unit as a basic spatial unit to capture smaller-scale information, to support regional and administrative level differences analysis, and to match the socioeconomic data of driving forces.

Regional- and Administrative-Level Differences Analysis. Regional- and administrative-level differences in urban landscape changes were also examined in this study. To capture regional differences, 2233 county units were divided into three regions: Eastern, Central, and Western (see Table 2 and Supporting Information Figure S2). City and county are different administrative-level units in China. A city is a hierarchical urban administrative region unit, whereas a county is a rural administrative region unit dominated by rural areas and a rural economy. Because of differentiation of development policy, cities and counties have various differences related to urban landscape patterns. Therefore, based on China's current administrative hierarchy, we divided data into city and county levels to distinguish these differences at the administrative level (SI, Figure S3).

Driving Forces and Their Data Sources. We extend the previous analytical framework of driving forces for urban landscape changes. This framework can be described using the hexagon determinants of geography, socio-economy, infrastructure, administrative level, policy, and history and includes ten quantitative variables. Table 2 shows a detailed description for this hexagon framework and the variables.

The geographical factors contain two quantitative variables. The administrative area (AREA) is a basic geographical factor and may have evolved as a constrained variable for urban landscape dynamic change, especially for a city with limited development space. This variable was collected for the year of 2005. The regional dummy variable (REGION) is a locational factor representing urban landscape change magnitude and is affected by external location and the development environment.

Socioeconomic factors include four driving forces, population (LNPOP), urbanization (URBAN), GDP per capita (LNGDP), and local financial revenue per capita (LNREV). For a country of China's size, population is the crucial factor in urban landscape changes. Urbanization means a growth of the urban population in urban areas and increasing demand for construction land; subsequently, these demands drive micro changes in the urban landscape through urban renewal in urban areas and urban expansion on the urban fringes. We expect that per-capita GDP might be the most important variable driving rapid change in the urban landscape. Economic development impulses often shape the urban form itself in China, because economic development is usually the supreme target of local government. This rapid pace of urban landscape change is driven by Chinese cities' overreliance on income from "local land finance." Local financial revenue per capita (LNREV) is a 


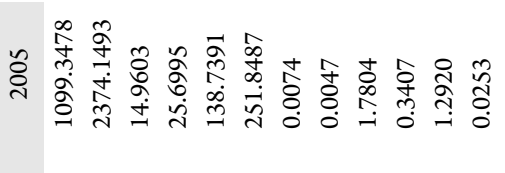

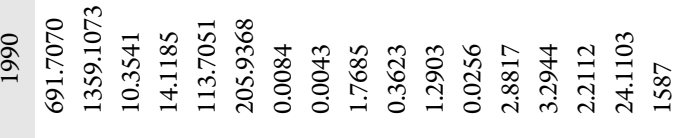

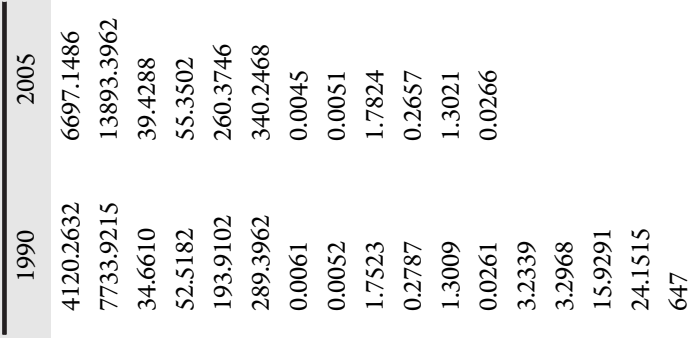

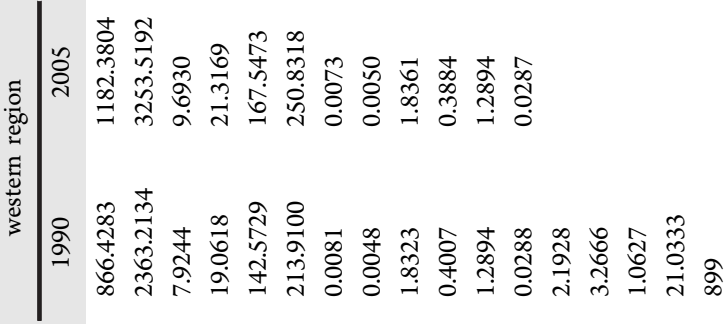

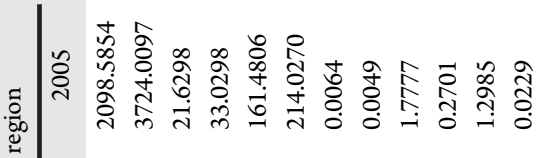

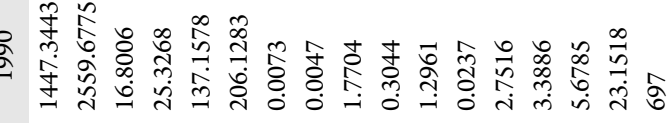

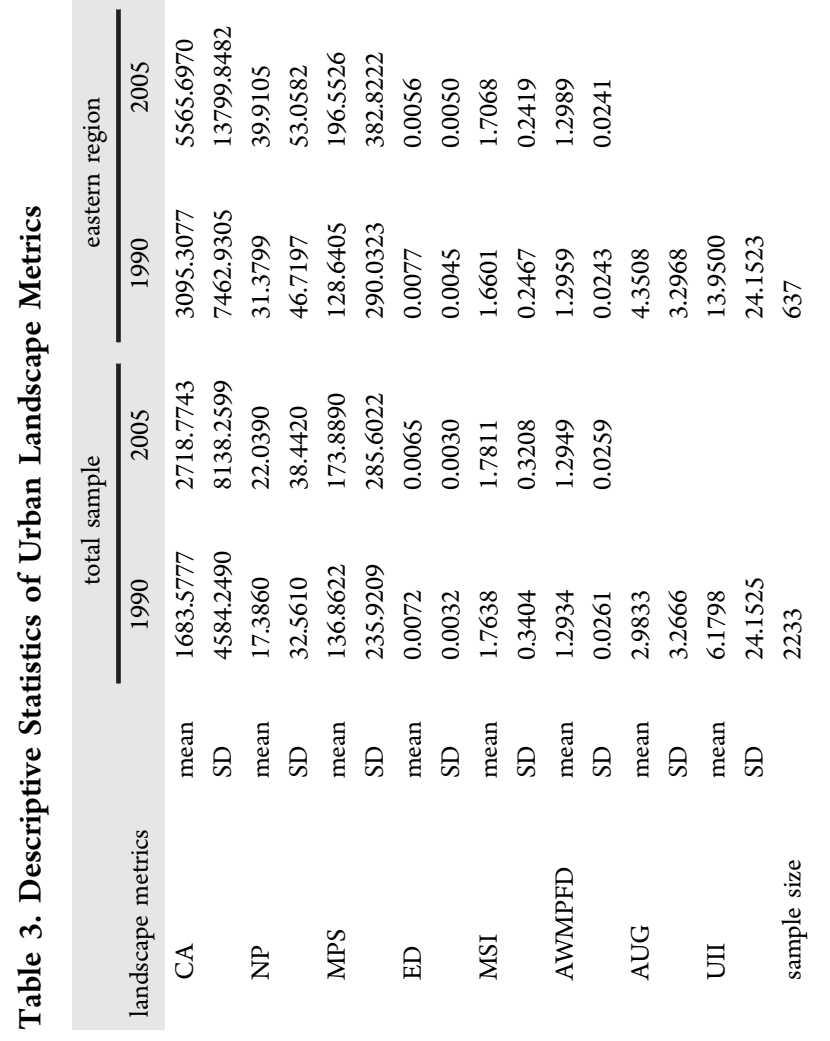


basic fund guarantee for urban development. All of the data were collected for 1992 and 2005.

The infrastructure factor includes one index. Road density (LNROAD), which intensified in the past 30 years to improve transportation accessibility in China, has important impacts on urban landscape expansion and fragmentation. Roads, as one of several landscape elements, directly cause landscape fragmentation. Thus, road density was selected as a direct influencing factor. ${ }^{65}$ However, because of limitations of more-refined road data, the high-grade road data set used in this paper includes railways, highways and national roads.

The administrative level factor also includes one variable. A city and county dummy variable (CITY) was used to characterize the administrative-level difference between city and county. To some extent, this difference is an obvious representation of China's dual urban-rural structure.

Policy factor (POLICY) is often a neglected variable. This paper focuses on national strategies and regional policies, statelevel economic development zones, and location in a country's urban system and development orientation for Development Priority Zones (2011). We used the method of Demurger et al. $^{66}$ and $\mathrm{Li}$ and Fang ${ }^{58}$ to quantitate the qualitative issue (see SI Text S2 for details of description).

The historical factor (HISTORY) is also a frequently neglected factor. Although external factors such as socioeconomic driving force were crucial, they could not play important roles without local and regional historical foundations. Thus, more attention should be devoted to the effect of a long accumulation of local and regional comprehensive elements and self-organization on urban landscape change.

Spatial Econometric Model for Driving Forces Analysis. In recent years, the spatial econometrics model has attracted a great deal of attention in spatial and geographic data analysis. ${ }^{67}$ Here we employed the joint spatial lag and error model to consider the spatial heteroskedasticity and spatial dependence of the error terms for a driving forces analysis of changing urban landscape. Unlike the ordinary least-squares (OLS) model, the dominant advantage of incorporated spatial error and spatial lag models is that they can effectively control the spatial dependency in the form of lag and error dependence to ensure estimation accuracy. ${ }^{68}$ The spatial lag and error model was formulated as follows:

$$
y=\rho W y+X \beta+\mu, \quad \mu=\lambda W \mu+\varepsilon
$$

where $y$ represents the dependent variables: the rate of change of selected urban landscape metrics between 1990 and 2005 for each county (see SI Figure S4). For the period from 1990 to 2005, data for 2233 Chinese counties were available. The rate of changes in the urban landscape metrics were computed as follows:

$$
C_{i}=\frac{\left(M_{2}-M_{1}\right)}{M_{1}} \times 100
$$

$W$ is a $(N \times N)$ block diagonal matrix, and the individual elements of $W=\left\{w_{i j}\right\}$. The scalar parameter $\rho$, a coefficient on the spatially lagged dependent variable provides a measure of influence for neighboring counties' rate of change of selected urban landscape metrics on the change rate of county $i$. This parameter must take on values less than one, the feasible range of $\rho$ was -1 to 1 , and in spatial regressions we would expect to see positive spatial dependence, indicating that the rates of change of selected urban landscape metrics are positively related to a linear combination of those from neighboring counties. $\lambda$ is the spatial autocorrelation coefficient that expresses the intensity of spatial autocorrelation (interdependences) in the error term analogous to the serial correlation problem in time series models. $X$ is the vector of explanatory variables and includes ten variables (see SI Figure S5). $W \mu$ is the spatial lag of the errors. $\varepsilon$ is a "well-behaved" error, with mean 0 and variance matrix $\sigma^{2}$. The inclusion of additional endogenous explanatory variables $(Y)$ leads to the following model:

$$
y=\rho W y+\mathrm{X} \beta+\gamma Y+\mu, \quad \mu=\lambda W \mu+\varepsilon
$$

Spatially weighted two-stage least-squares (S2SLS) plus generalized method of moments (GMM) estimation of the joint spatial lag and spatial error model without/with endogenous regressors was used in this spatial econometric model. This estimation model is designed to take both spatial heteroskedasticity and autocorrelation (KP-HET), proposed by Kelejian and Prucha, ${ }^{69}$ into account. The GeoDaSpace 1.0 software package for the estimation and testing of spatial econometric models was employed (https://geodacenter.asu. edu/software/downloads/geodaspace, technical details can be found in previous works ${ }^{67}$ ).

\section{RESULTS AND DISCUSSION}

Dynamic Patterns of Urban Landscape. Between 1990 and 2005, China experienced an accelerating process of urbanization and industrialization, which caused its urban landscape pattern to experience a series of drastic changes (Table 3). From an absolute size perspective, total urban area (CA) has increased exponentially from 37594 to $60710 \mathrm{~km}^{2}$, and expanded approximately 1.61 times, with an annual increase of $1541 \mathrm{~km}^{2}$ during the period from 1990 to 2005 . Generally, considering the growth rate and spatial orientation of the development, extensive expansion was the primary form of urban growth, resulting in an explosive increase in the number of urban patches (NP) between 1990 and 2005-from 38823 to 49213 , an increase of $26.76 \%$. This suggests that urban growth became more fragmented. This result was consistent with previous findings. ${ }^{27,35,70}$ However, from a relative size perspective, MPS increased for all urban landscape, which does not represent a more fragmentary shape change. MPS increased 27.06\% from 1990 to 2005, which indicates that the average patch size increased. This also suggests many small rural or other patches originally located in the urban and suburban areas might have been converted to urban use, resulting in larger patches on the urban fringes. ${ }^{71}$ In other words, urban in-filling and edge expansion, not leapfrog development, was dominant. These results may differ from other studies on single cities. ${ }^{27,41}$

Based on the aforementioned different results for landscape fragmentation, a combination analysis for NP and MPS is essential to clarify this inconsistency because the aggregate process of individual landscape metrics could result in averaging, offsets and a partial lack of information. In concrete terms, there are four combination types of NP and MPS. It is generally recognized that increasing NP mirrors a trend toward fragmentary urban landscape. This, combined with a decrease in MPS, can be used to deduce that new urban expanding areas are smaller than existing neighborhoods (accounting for $22.35 \%$ of 2233 counties), which indicates that the degree of fragmentation of patches increased. ${ }^{18}$ An increase in the value of NP and MPS may be indicative of urban land subdivisions 


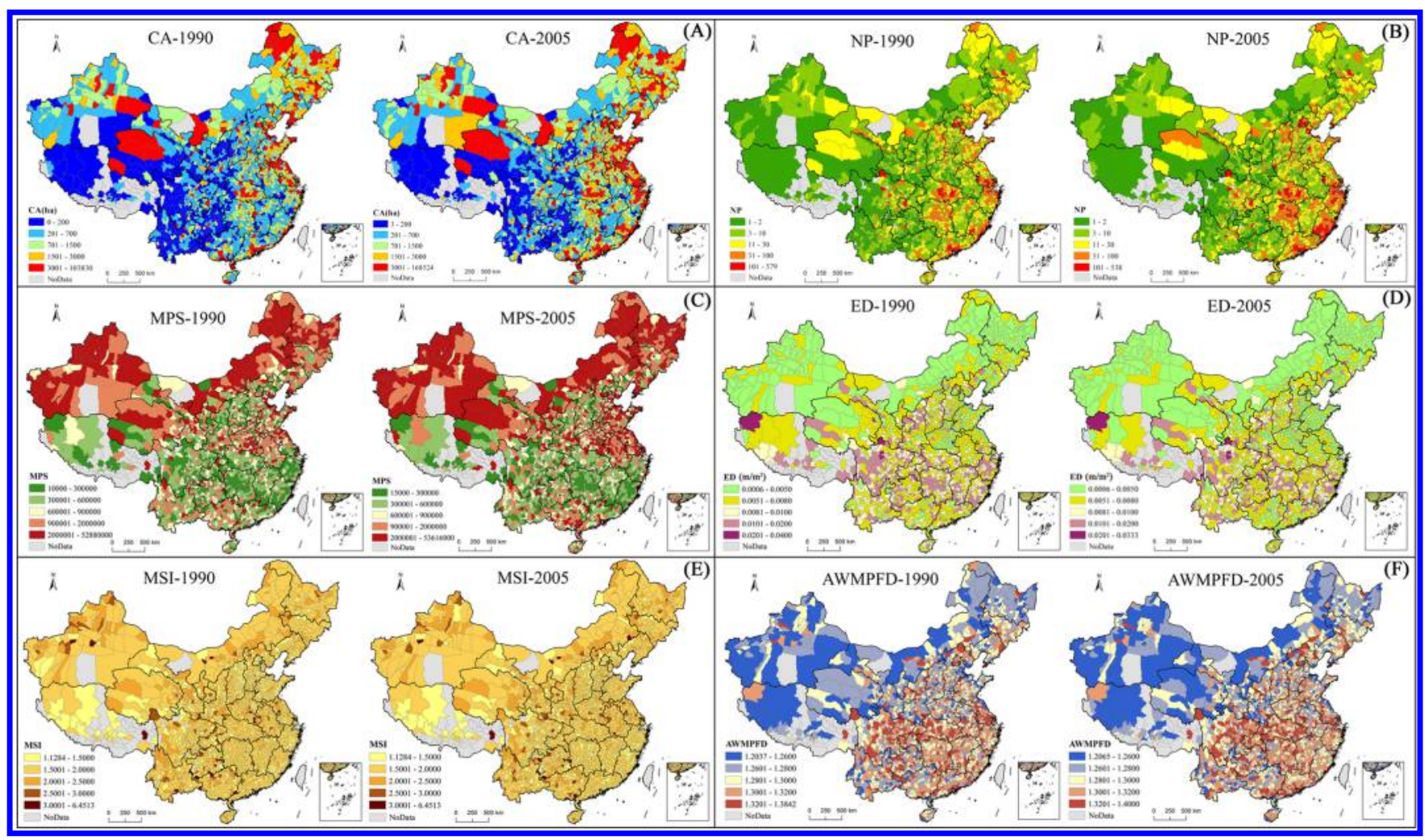

Figure 1. Urban landscape metrics changes between 1990 and 2005.

such as planned unit developments (accounting for $26.51 \%$ of all counties), which does not represent a more fragmentary landscape change. A decrease in the value of NP coupled with an increase in MPS is a symbol of urban landscape congregate development and infill-expansion (accounting for $20.24 \%$ of all counties). An increase in MPS without a decrease in the NP is indicative of contiguous or contagious expansion (accounting for $19.84 \%$ of all counties). Thus, we concluded that there was a decreasing level of fragmentation of the urban landscape from 1990 to 2005 based on this combination analysis of NP and MPS. To further examine the heterogeneity of landscape metrics, SI Text S3 and Figure S6 show a detailed combination analysis for urban landscape metrics.

ED for urban landscape retained a downward trend; the value decreased $9.72 \%$ from 1990 to 2005 . This finding further indicates that urban landscape expansion became contiguous under the rapid urbanization process. ED declined for overall urban landscape, implying that urban areas fused together in China. This result may further confirm the universality and reliability of studies in the Pearl River Delta. ${ }^{3}$

MSI and AWMPFD for total urban area retained a slight upward trend from 1990 to 2005 . This reveals that either the urban landscape was becoming more irregular and complex or the spatial heterogeneity was increasing in shape, which implies the unplanned growth of urban areas. ${ }^{27}$ These findings further indicate the urban landscape became more complex as fragmentation decreased, resulting from a whole urban area's clumped development at the national level.

AUG was $2.98 \%$ for total urban landscape over the 15 -year interval. The UII was $6.18 \%$, meaning there was very low urbanization intensity. On the national scale, this implies that although the urban landscape experienced a rapid change process, urbanization intensity did not reach a high level.
Comparison Among Regions and Administrative Levels. Comparison of landscape metrics among various regions enabled a more detailed observation of how the urban landscape changed, which can help with decision-making. Between 1990 and 2005, urban areas in eastern counties increased by $79.81 \%$, whereas in central and western counties, they grew by $45.00 \%$ and $36.47 \%$, respectively. Regional differences in urban landscape notwithstanding, the heterogeneous size of the average urban area of individual cities was remarkable. In 2005, the counties with larger urban areas were predominantly in Beijing, Tianjin, Shandong, Jiangsu, Zhejiang, Fujian, Guangdong, central Hubei, southern Liaoning, and northwest Qinghai (Figure 1A). Unsurprisingly, counties in the eastern region had a larger average urban area size than counties in the central and western regions (see Table 3). This is likely attributable to the existence of a relatively long development history of urban land in the eastern counties and the strong driving forces of the "reform and openness" policy. ${ }^{72}$ Thus, these regions also prioritized the prevention and control of rapid urban expansion. ${ }^{73}$ In the case of NP, a similar changing trend was found among various regions compared to the national level. Although the NP of all three regions increased from 1990 to 2005, the magnitude of changes was different. Overall, the largest increases of NP were observed in the eastern counties. In terms of spatial distribution, the Yangtze River Delta, the Pearl River Delta, Fujian, Hubei and Hunan were primary focus areas. Therefore, these regions will be the subjects of strict management for urban landscape fragmentation. $^{74}$

Because of the aggregation of urban areas, MPS increased in three regions. Between 1990 and 2005, the rate of change of this metric in eastern counties witnessed the most rapid growth of $52.79 \%$, whereas the central and western counties experienced more moderate growth, with rates of $17.73 \%$ and 


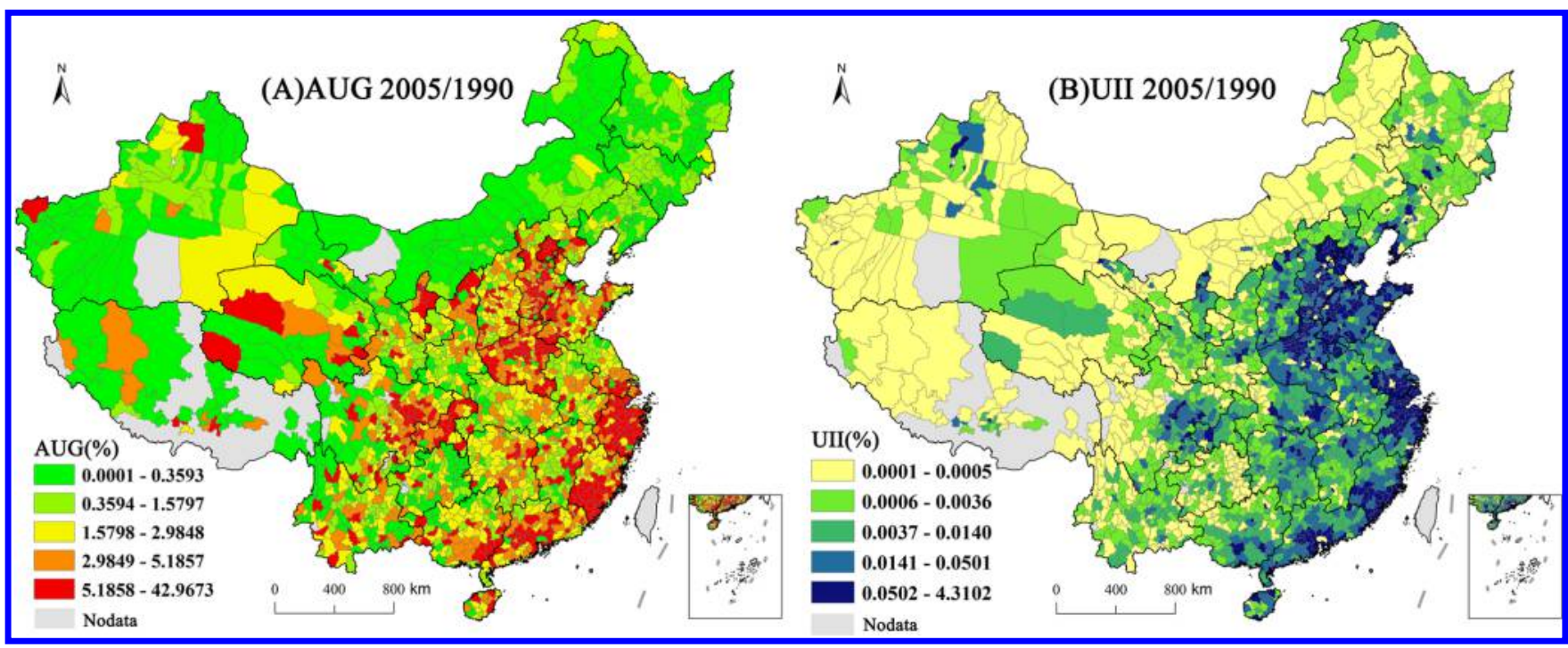

Figure 2. Spatial distribution of annual rates of urban area growth (AUG) and urbanization intensity index (UII) from 1990 to 2005.

Table 4. Relationships between Urban Landscape Metrics and Explanatory Variables ${ }^{a}$

\begin{tabular}{|c|c|c|c|c|c|c|c|c|}
\hline \multirow{2}{*}{$\begin{array}{l}\text { independent } \\
\text { variable } \\
\text { (\% change) }\end{array}$} & \multicolumn{8}{|c|}{ dependent variable (\% change) } \\
\hline & $\mathrm{CA}$ & $\mathrm{NP}$ & MPS & $\mathrm{ED}$ & MSI & AWMPFD & AUG & UII \\
\hline constant & $8.0776^{* * *}$ & 0.1570 & $5.3011^{* * *}$ & 0.0272 & $0.3448^{* * *}$ & $0.1579 * * *$ & $1.5156^{*}$ & $0.2640 * * *$ \\
\hline LNAREA & -0.0194 & -0.0119 & -0.1427 & $0.0124 * * *$ & $-0.0098 * * *$ & $-0.0009 * * *$ & $-0.2483 * * *$ & $-0.0401^{* * *}$ \\
\hline REGION & -0.0536 & $0.1847^{* * *}$ & 0.0874 & $-0.0094 * *$ & -0.0084 & -0.0001 & $0.1675^{* *}$ & 0.0094 \\
\hline LNPOP & $0.0042^{*}$ & 0.0008 & $0.0032^{* * *}$ & $-0.0003 * *$ & 0.0000 & 0.0001 & $0.0054 * * *$ & $0.0010 * * *$ \\
\hline URBAN & 0.0032 & 0.0016 & 0.0063 & 0.0002 & -0.0003 & 0.0001 & 0.0033 & $0.0020 * * *$ \\
\hline LNGDP & $0.0030^{* *}$ & $0.0010^{*}$ & $0.0031^{* *}$ & $-0.0002 *$ & $0.0002 * * *$ & 0.0001 & $0.0050^{* * *}$ & $0.0041^{* * *}$ \\
\hline LNREV & 0.0030 & -0.0001 & 0.0018 & $-0.0002 * * *$ & $-0.0001^{*}$ & 0.0001 & $0.0023 * * *$ & $0.0002 * * *$ \\
\hline LNROAD & $0.0009^{*}$ & 0.0001 & -0.0001 & 0.0001 & 0.0001 & 0.0001 & 0.0001 & 0.0001 \\
\hline CITY & $1.4542^{*}$ & -0.0293 & $0.4357 * * *$ & $-0.0480 * * *$ & 0.0059 & $0.0009^{*}$ & $0.1852^{*}$ & $0.0723^{* * * *}$ \\
\hline POLICY & $0.3386^{* * *}$ & 0.0453 & -0.0601 & $-0.0115^{*}$ & -0.0022 & $0.0009^{* * *}$ & 0.0420 & 0.0148 \\
\hline HISTORY & $-1.0590^{* * *}$ & $-0.1860^{* * *}$ & $-0.3437 * * *$ & $-12.0693^{* * *}$ & $-0.1412 * * *$ & $-0.1171^{* * *}$ & & \\
\hline$\rho$ & $-0.4105 * * *$ & $0.5013^{* * *}$ & 0.1814 & $0.3125 * * *$ & -0.0516 & $0.9046^{* * *}$ & $0.6924 * * *$ & 0.3691 \\
\hline$\lambda$ & $0.5423 * * *$ & $-0.6219^{* * *}$ & $-0.5144^{* *}$ & $-0.2282 * *$ & $0.4927^{* * *}$ & $-0.8900^{* * *}$ & $-0.7569 * * *$ & $-0.7419^{* * *}$ \\
\hline$\underset{R^{2}}{\text { spatial pseudo }}$ & 0.5751 & 0.4818 & 0.4342 & 0.4319 & 0.3385 & 0.3149 & 0.5162 & 0.4696 \\
\hline observations & 2233 & 2233 & 2233 & 2233 & 2233 & 2233 & 2233 & 2233 \\
\hline
\end{tabular}

$17.52 \%$, respectively. This stair-stepping urban landscape change pattern was consistent with macro regional development strategy and the unbalanced development of regional economies. ${ }^{73}$ From the perspective of spatial heterogeneity, the high values of MPS clustered in north counties such as Shandong, Henan, Jiangsu, Anhui, Xinjiang, Inner Mongolia, and three provinces in the northeast of China (Figure 1C). The low values of MPS clustered in Zhejiang, Fujian, Jiangxi, Hubei, Hunan, Guangdong, and the southwest of China, where more attention should be devoted to preventing the occurrence of a more fragmented urban landscape.

Although urban area development in the various regions is heterogeneous, the change trends for ED are similar. The observed results reveal that the three regions all had a significant, decreasing ED trend over this time period. They indicated lower fragmentation of the urban landscape in 2005. Regional variation in ED indicated that eastern counties are the most aggregated and continuous, and central counties are superior to western counties. Therefore, with rapid progress in industrialization and urbanization it is crucial to pay extra attention to the intensive and compact development of urban areas in central and western counties. In concrete terms, spatial gathering regions of high ED value are the focuses of urban land governance, for example, in the Southwest and Central China regions (Figure 1D).

From the perspective of regional differences, MSI for urban landscape increased differently during the study period. The mean values of MSI in various regions (Table 3) from high to low were in the order of western region, central region and eastern region, indicating that the western counties had the most complex, irregular urban land shapes. However, this finding is not supported by the changes of AWMPFD value in various regions. In general, the value of AWMPFD in eastern counties was higher than in other counties. Spatially, the spatial distribution of AWMPFD follows the "Hu Huanyong Line," an important geographical boundary for China's population density. The southeast side of the $\mathrm{Hu}$ Huanyong Line represents the high-value concentrated region for AWMPFD 
(Figure 1E-F) where we should be concerned about urban landscape complexity, especially in the Yangtze River Basin, Guangdong and Fujian.

The AUG and UII also showed a significant stair-stepping difference (Figure 2). On average, the annual rate of urban growth was $4.35 \%$ in eastern counties between 1990 and 2005 . This was higher than in central and western counties. ${ }^{73}$ Nevertheless, the central and western counties showed growth rates of $2.75 \%$ and $2.19 \%$, respectively. In the case of UII, a similar changing trend was found among various regions. This is the result of rapid economic development and high-speed urbanization processes leading to increasing demand for urban construction, industrial development and housing. Spatially, the North China Plain, the Yangtze River Delta, the Pearl River Delta, Fujian, and the Chengdu-Chongqing region were prominent high-value clustering areas of AUG and UII.

For the differences in counties and cities that are calculated by total urban areas, $2005 \mathrm{CA}$ in cities accounted for $71.26 \%$ with 646 cities, whereas counties only accounted for $28.74 \%$ with 1,587 counties. In general, cities have higher NP, MPS and AWMPFD value than counties (Table 3 ). These findings reveal that the urban landscape pattern in cities exhibits the most complex, least fragmented and most aggregate characteristics. Counties display diametrically opposed tendencies. Meanwhile, we also found several striking characteristics in changing urban landscape patterns. The UII in cities was 15.93 , approximately 7.2 times its value in counties (2.21). Urban areas in cities account for $2.25 \%$ of the total area. However, the built-up area covered only $0.26 \%$ of the total area in counties. This clearly indicated that although administrative level impacts urban landscape patterns, urban size, and hierarchy also have effects.

Driving Forces Behind Changing Urban Landscape. To examine the driving mechanism behind changing urban landscape patterns, we regressed 2233 county-level administrative units using selected geographical indicators, socioeconomic factors, infrastructure variables, administrative level factors, policy factors, and historical factors (Table 4). In general, the spatial pseudo $R^{2}$ of these models was moderate. Pursuant to the work of $\mathrm{Kaza}^{28}$ this suggests that the socioeconomic factors and landscape metrics are orthogonal. Thus, using compound information about landscape metrics and explanatory variables will give a more complete picture of China's changing urban landscape. Meanwhile, we found significant spatial dependence in all spatial econometric models. This result confirms the necessity of using a spatial econometric model in regression analysis.

LNAREA is statistically significant for ED, MSI, AWMPFD, AUG, and UII. This indicates that increases in counties' total administrative area result in less contiguous and congregated patterns of urban development and a decrease in the complexity of urban landscape, the annual rate of urban growth, and urbanization intensity. This result implies that a larger administrative area is usually a constraining factor for intensive urban land use because it can provide more available space for extended and expanding urban development. In addition, the regression result reveals that the REGION variable is similar to regional difference analysis of urban landscape. The region dummy is statistically significant for three landscape metrics. Eastern counties show an increase in the number of patches, a decrease in the edge density, and a higher increase in annual rates of urban area growth than do the central and western counties.
The greater the population change, the more a county's urban areas increase, urban mean patch sizes increase, urban edge density decreases, annual rate of urban growth increases, and urbanization density increases. This result is consistent with the results of similar studies in support of demographic changes directly influencing urban landscape pattern changes. ${ }^{51}$ The economic gap and dualization between rural and urban areas, along with more employment opportunities in cities, induced mass population migration from rural to urban areas, leading to rapid increases in urban land use. Surprisingly, the change in urbanization levels has a nonsignificant influence on the changes in urban landscape in the counties. Urbanization is only correlated to the changes in UII. The main reason is quite likely that the urbanization level refers to the proportion of rural and urban populations in registered residences ("hukou"). Not surprisingly, the GDP per capita variable is statistically significant for seven landscape metrics. Rapid economic growth dramatically spurs increases in urban areas and the number of urban patches increase. ${ }^{49,51}$ Increases in GDP per capita result in more contiguous, congregate, and complex patterns of urban development. Moreover, the econometric analysis showed that GDP per capita had positive effects on the increase of AUG and UII. The inference is also supported by the regression result of LNREV.

The infrastructure factor, represented by road density, is not a statistically significant variable for most regression models. This is a counterintuitive finding. The LNROAD variable is only correlated to an increase in the total urban areas, which demonstrates that traffic improvement directly impacts urban areas' growth. In China, investment in infrastructure gradually evolved into an important push to promote urban land expansion. For other urban landscape metrics, the coefficients were not significant. The most probable cause is the high-grade road data set used in this study; it includes railways, highways and national roads. However, for urban landscape, these highgrade roads serve long distance interurban travelers, not movement within the city or urban fringe. Therefore, their effects on urban landscape were often restricted, especially compared to inner-city roads. Unfortunately based on Landsat TM and Landsat ETM scenes with a spatial resolution of $30 \mathrm{~m}$ $\times 30 \mathrm{~m}$, China's current national urban land-use data are unable to effectively obtain information about inner-city roads.

The CITY dummy variable is statistically significant for six regression models. The administrative level often determines preferences for policies and resource allocation in China. The development of cities has advantages compared to counties, and previous research has arrived at similar results for the U.S. ${ }^{28}$ Therefore, cities experienced more obvious urban landscape changes than counties.

Our regression result reveals that the POLICY variable is statistically significant for CA, ED, and AWMPFD. Increases in policy preference result in larger total urban areas and more contagious and complex urban expansion shapes, perhaps because policy preference is a powerful economic growth driving force in China both to greatly expand urban areas and to induce unplanned growth. Our results also implied that preferential policies have strongly promoted urban areas' expansion, at least to an extent. The policies of stimulating industry development and attracting foreign investment are two efficient methods of driving economic growth, leading to dynamic changes in the urban landscape. POLICY is not significant for other landscape metrics such as NP and MPS. This result is primarily because macroscopic policies were 
ineffective at directly changing microscopic urban forms in shape and fragmentation.

To analyze the effects of the history factor, we incorporated the value of landscape metrics in 1990 into our models. Table 4 shows that the history factor is significantly and negatively related to the changes in urban landscape patterns. This effect is primarily caused by the embeddedness of urban landscape changes; in other words, it is difficult to change to change an urban landscape once a pattern has been formed.

To examine the reliability of our results, we also conducted a preliminary uncertainty analysis (see SI Text S4).

Policy Implications of Urban Landscape Changes. This study has significant policy implications for China. As we found, regional- and administrative-level differences in changing urban landscape patterns have intensified in the context of rapid urbanization. To formulate effective urban landscape policies, future decision-makers should adequately consider differences in region, urban size and hierarchy. This decision-making process may help end the traditional "one size fits all" policies. For example, for fragmentary and irregular urban expansion in western and central counties, it is crucial both to strengthen landscape governance and to undertake the intensive and compact development of urban areas.

Our driving forces analyses for changing urban landscape imply that urban economic growth demands frantic urban land expansion and additional land supply in China under rapid urbanization processes. In other words, urban China's current economic growth pattern is highly dependent on land resource input. ${ }^{9}$ However, steady, rapid economic growth is always the primary goal of Chinese urban decision makers. The prerequisite of making differential feasible urban landscape policies is to maintain economic development. Therefore, Chinese local governments remain challenged by urban landscape governance to control blind urban expansion while maintaining economic growth in cities where rapid development is still necessary and important. Fundamentally, it is certain that urban China will transform its urban economic growth pattern and improve the efficiency of its urban land to achieve sustainable development. Meanwhile, the regression results of policy and road density variables are not without policy caveats. In a regression analysis of POLICY, this variable did not influence several landscape indices (NP, MPS, etc.), indicating that macroscopic policies play a lesser role in changing certain aspects of the landscape, such as shape and fragmentation. From the perspective of urban forms management, our result means that microscopic policy such as spatial distribution of functional areas and the urban design of individual cities, seems to be a more effective way to change urban forms. For regression analysis of LNROAD, high-grade roads have not had significant impacts on urban landscape changes, which implies that high-grade road planning and design may not be more effective than inner-city roads for urban landscape management.

It is well-known that using urban planning tools to manage urban landscape is the most effective measure. We think that three key points must be considered. On the one hand, as found in this study, the implementation of urban planning is an important task at China's current development stage for urban landscape management. Thus, the top priority for China's cities is to strengthen the management of urban planning. On the other hand, for urban planners, compact and congregate urban landscape might be a good choice for urban development patterns. Designing rational urban forms may be an effective way to address the problem of the unreasonable development of urban landscape. ${ }^{75,76}$ In addition, intensive urban land use is not only an important mission but also a major tool for urban planners in China. Moreover, based on the above driving forces analysis, policymakers for urban landscape should be aware of that accurate driving mechanism analysis. We hope that this study's empirical findings have important implications for the path toward developing sustainable urban forms in China (a sustainable urban form can be defined as having less complexity, a fewer number of patches, and a bigger patch size).

\section{ASSOCIATED CONTENT}

\section{S Supporting Information}

The Supporting Information is available free of charge on the ACS Publications website at DOI: 10.1021/acs.est.5b05198.

Additional information as noted in the text (PDF)

\section{AUTHOR INFORMATION}

\section{Corresponding Authors}

*E-mail: ligd@igsnrr.ac.cn. Tel.: +86-01064889101. Fax: +8601064889301 (G.L.).

*E-mail: wangshj8@mail.sysu.edu.cn. Tel.: +86-02064111475. Fax: +86-02064111475 (S.W.).

\section{Notes}

The authors declare no competing financial interest.

\section{ACKNOWLEDGMENTS}

We thank three anonymous reviewers for their insightful comments. This work was supported by Natural Science Foundation of China (grant nos. 41590842, 41501175, and 71433008).

\section{REFERENCES}

(1) Wu, J.; Jenerette, G. D.; Buyantuyev, A.; Redman, C. L. Quantifying spatiotemporal patterns of urbanization: The case of the two fastest growing metropolitan regions in the United States. Ecol Complex 2011, 8 (1), 1-8.

(2) Grimm, N. B.; Faeth, S. H.; Golubiewski, N. E.; Redman, C. L.; Wu, J. G.; Bai, X. M.; Briggs, J. M. Global change and the ecology of cities. Science 2008, 319 (5864), 756-760.

(3) Seto, K. C.; Fragkias, M. Quantifying spatiotemporal patterns of urban land-use change in four cities of China with time series landscape metrics. Landscape Ecol 2005, 20 (7), 871-888.

(4) World Urbanization Prospects: The 2014 Revision, CD-ROM ed.; United Nations; Department of Economic and Social Affairs; Population Division, 2014.

(5) Ramachandra, T. V.; Aithal, B. H.; Sanna, D. D. Insights to urban dynamics through landscape spatial pattern analysis. ITC J. 2012, 18, 329-343.

(6) Xu, C.; Liu, M.; Hong, C.; Chi, T.; An, S.; Yang, X. Temporal variation of characteristic scales in urban landscapes: an insight into the evolving internal structures of China's two largest cities. Landscape Ecol 2012, 27 (7), 1063-1074.

(7) Schneider, A.; Friedl, M. A.; Potere, D. A new map of global urban extent from MODIS satellite data. Environ. Res. Lett. 2009, 4, 044003.

(8) Lester, R. Eco-economy: Building an Economy for the Earth; Orient Blackswan: 2002.

(9) Bai, X. M.; Chen, J.; Shi, P. J. Landscape Urbanization and Economic Growth in China: Positive Feedbacks and Sustainability Dilemmas. Environ. Sci. Technol. 2012, 46 (1), 132-139.

(10) Seto, K. C.; Sánchez-Rodríguez, R.; Fragkias, M. The New Geography of Contemporary Urbanization and the Environment. Annual Review of Environment and Resources 2010, 35 (1), 167-194. 
(11) Civerolo, K.; Hogrefe, C.; Lynn, B.; Rosenthal, J.; Ku, J.-Y.; Solecki, W.; Cox, J.; Small, C.; Rosenzweig, C.; Goldberg, R; et al. Estimating the effects of increased urbanization on surface meteorology and ozone concentrations in the New York City metropolitan region. Atmos. Environ. 2007, 41 (9), 1803-1818.

(12) Van Metre, P. C.; Mahler, B. J.; Furlong, E. T. Urban sprawl leaves its PAH signature. Environ. Sci. Technol. 2000, 34 (19), 40644070.

(13) Stone, B., Jr Urban sprawl and air quality in large US cities. I. Environ. Manage. 2008, 86 (4), 688-698.

(14) Foley, J. A.; DeFries, R.; Asner, G. P.; Barford, C.; Bonan, G.; Carpenter, S. R.; Chapin, F. S.; Coe, M. T.; Daily, G. C.; Gibbs, H. K. Global consequences of land use. Science 2005, 309 (5734), 570-574.

(15) Liu, J.; Deng, X. Impacts and mitigation of climate change on Chinese cities. Curr. Opin Sust 2011, 3 (3), 188-192.

(16) Miao, S.; Chen, F.; LeMone, M. A.; Tewari, M.; Li, Q.; Wang, Y. An observational and modeling study of characteristics of urban heat island and boundary layer structures in Beijing. I. Appl. Meteorol Clim 2009, 48 (3), 484-501.

(17) Weng, Q.; Lu, D.; Schubring, J. Estimation of land surface temperature-vegetation abundance relationship for urban heat island studies. Remote Sens Environ 2004, 89 (4), 467-483.

(18) Pauchard, A.; Aguayo, M.; Peña, E.; Urrutia, R. Multiple effects of urbanization on the biodiversity of developing countries: the case of a fast-growing metropolitan area (Concepción, Chile). Biol. Conserv 2006, 127 (3), 272-281.

(19) Chen, J. Rapid urbanization in China: A real challenge to soil protection and food security. Catena 2007, 69 (1), 1-15.

(20) National Bureau of Statistics PRC. China Statistical Yearbook 2014, Chinese-English ed.; China Statistics Press: 2014.

(21) National Bureau of Statistics PRC; Urban social and economic investigation department. China City Statistical Yearbook 2014; China Statistics Press: 2014.

(22) National Bureau of Statistics PRC; Urban social and economic investigation department. China City Statistical Yearbook 1986; China Statistics Press: 1986.

(23) Zhao, S.; Zhou, D.; Zhu, C.; Sun, Y.; Wu, W.; Liu, S. Spatial and Temporal Dimensions of Urban Expansion in China. Environ. Sci. Technol. 2015, 49 (16), 9600-9609.

(24) McGarigal, K.; Marks, B. J. FRAGSTATS Spatial pattern analysis program for quantifying landscape structure; 1994, p 67.

(25) O’Neill, R. V.; Krummel, J. R.; Gardner, R. H.; Sugihara, G.; Jackson, B.; DeAngelis, D. L.; Milne, B. T.; Turner, M. G.; Zygmunt, B.; Christensen, S. W.; Dale, V. H.; Graham, R. L. Indices of landscape pattern. Landscape Ecol 1988, 1 (3), 153-162.

(26) Yu, X.; Ng, C. An integrated evaluation of landscape change using remote sensing and landscape metrics: a case study of Panyu, Guangzhou. Int. I. Remote Sens 2006, 27 (6), 1075-1092.

(27) Qu, W.; Zhao, S.; Sun, Y. Spatiotemporal patterns of urbanization over the past three decades: a comparison between two large cities in Southwest China. Urban Ecosvst 2014, 17 (3), 723-739.

(28) Kaza, N. The changing urban landscape of the continental United States. Landscape Urban Plan 2013, 110 (0), 74-86.

(29) Aguilera, F.; Valenzuela, L. M.; Botequilha-Leitão, A. Landscape metrics in the analysis of urban land use patterns: A case study in a Spanish metropolitan area. Landscape Urban Plan 2011, 99 (3), 226238.

(30) Schwarz, N. Urban form revisited-Selecting indicators for characterising European cities. Landscape Urban Plan 2010, 96 (1), 29-47.

(31) Taubenböck, H.; Wegmann, M.; Roth, A.; Mehl, H.; Dech, S. Urbanization in India-Spatiotemporal analysis using remote sensing data. Computers, Environment and Urban Systems 2009, 33 (3), 179188.

(32) Weng, Y.-C. Spatiotemporal changes of landscape pattern in response to urbanization. Landscape Urban Plan 2007, 81 (4), 341353.
(33) Huang, J. G.; Lu, X. X.; Sellers, J. M. A global comparative analysis of urban form: Applying spatial metrics and remote sensing. Landscape Urban Plan 2007, 82 (4), 184-197.

(34) Li, X.; Yeh, A. G. O. Analyzing spatial restructuring of land use patterns in a fast growing region using remote sensing and GIS. Landscape Urban Plan 2004, 69 (4), 335-354.

(35) Herold, M.; Goldstein, N. C.; Clarke, K. C. The spatiotemporal form of urban growth: measurement, analysis and modeling. Remote Sens Environ 2003, 86 (3), 286-302.

(36) Luck, M.; Wu, J. G. A gradient analysis of urban landscape pattern: a case study from the Phoenix metropolitan region, Arizona, USA. Landscape Ecol 2002, 17 (4), 327-339.

(37) Herold, M.; Scepan, J.; Clarke, K. C. The use of remote sensing and landscape metrics to describe structures and changes in urban land uses. Environ. Plann A 2002, 34 (8), 1443-1458.

(38) Xie, Y.; Yu, M.; Bai, Y.; Xing, X. Ecological analysis of an emerging urban landscape pattern-desakota: a case study in Suzhou, China. Landscape Ecol 2006, 21 (8), 1297-1309.

(39) Li, Y.; Zhu, X.; Sun, X.; Wang, F. Landscape effects of environmental impact on bay-area wetlands under rapid urban expansion and development policy: a case study of Lianyungang, China. Landscape Urban Plan 2010, 94 (3), 218-227.

(40) Yeh, C. T.; Huang, S. L. Investigating spatiotemporal patterns of landscape diversity in response to urbanization. Landscape Urban Plan 2009, 93 (3-4), 151-162.

(41) Tian, G. J.; Jiang, J.; Yang, Z. F.; Zhang, Y. Q. The urban growth, size distribution and spatio-temporal dynamic pattern of the Yangtze River Delta megalopolitan region, China. Ecol. Modell. 2011, 222 (3), 865-878.

(42) Jiang, L.; Deng, X. Z.; Seto, K. C. Multi-level modeling of urban expansion and cultivated land conversion for urban hotspot counties in China. Landscape Urban Plan 2012, 108 (2-4), 131-139.

(43) Wu, J. Urban ecology and sustainability: The state-of-the-science and future directions. Landscape Urban Plan 2014, 125, 209-221.

(44) Gu, C.; Wu, L.; Cook, I. Progress in research on Chinese urbanization. Frontiers of Architectural Research 2012, 1 (2), 101-149.

(45) Dewan, A. M.; Yamaguchi, Y. Land use and land cover change in Greater Dhaka, Bangladesh: Using remote sensing to promote sustainable urbanization. Appl. Geogr 2009, 29 (3), 390-401.

(46) Zhang, Z.; Su, S.; Xiao, R.; Jiang, D.; Wu, J. Identifying determinants of urban growth from a multi-scale perspective: A case study of the urban agglomeration around Hangzhou Bay, China. Appl. Geogr 2013, 45 (0), 193-202.

(47) Estoque, R. C.; Murayama, Y. Landscape pattern and ecosystem service value changes: Implications for environmental sustainability planning for the rapidly urbanizing summer capital of the Philippines. Landscape Urban Plan 2013, 116 (0), 60-72.

(48) Xiao, J.; Shen, Y.; Ge, J.; Tateishi, R.; Tang, C.; Liang, Y.; Huang, Z. Evaluating urban expansion and land use change in Shijiazhuang, China, by using GIS and remote sensing. Landscape Urban Plan 2006, 75 (1-2), 69-80.

(49) Liu, J.; Zhan, J.; Deng, X. Spatio-temporal patterns and driving forces of urban land expansion in China during the economic reform era. Ambio 2005, 34 (6), 450-455.

(50) Su, S.; Xiao, R.; Jiang, Z.; Zhang, Y. Characterizing landscape pattern and ecosystem service value changes for urbanization impacts at an eco-regional scale. Appl. Geogr 2012, 34, 295-305.

(51) Deng, X. Z.; Huang, J. K.; Rozelle, S.; Uchida, E. Economic Growth and the Expansion of Urban Land in China. Urban Stud 2010, 47 (4), 813-843.

(52) Yue, W.; Fan, P.; Wei, Y. D.; Qi, J. Economic development, urban expansion, and sustainable development in Shanghai. Stoch Env Res. Risk A 2014, 28 (4), 783-799.

(53) Ma, Y. L.; Xu, R. S. Remote sensing monitoring and driving force analysis of urban expansion in Guangzhou City, China. Habitat Int. 2010, 34 (2), 228-235.

(54) Batisani, N.; Yarnal, B. Urban expansion in Centre County, Pennsylvania: Spatial dynamics and landscape transformations. Appl. Geogr 2009, 29 (2), 235-249. 
(55) Deng, X.; Huang, J.; Rozelle, S.; Uchida, E. Growth, population and industrialization, and urban land expansion of China. L. Urban Econ 2008, 63 (1), 96-115.

(56) Yue, W.; Liu, Y.; Fan, P. Measuring urban sprawl and its drivers in large Chinese cities: The case of Hangzhou. Land Use Policy 2013, $31,358-370$.

(57) Fan, C.; Myint, S. A comparison of spatial autocorrelation indices and landscape metrics in measuring urban landscape fragmentation. Landscape Urban Plan 2014, 121 (0), 117-128.

(58) Li, G. D.; Fang, C. L. Analyzing the multi-mechanism of regional inequality in China. Ann. Regional Sci. 2014, 52 (1), 155-182.

(59) Liu, J.; Zhang, Z.; Xu, X.; Kuang, W.; Zhou, W.; Zhang, S.; Li, R.; Yan, C.; Yu, D.; Wu, S.; Jiang, N. Spatial patterns and driving forces of land use change in China during the early 21 st century. L. Geogr Sci. 2010, 20 (4), 483-494.

(60) Liu, J. China’s changing landscape during the 1990s: Large-scale land transformations estimated with satellite data. Geophys. Res. Lett. 2005, 32 (2), L02405.

(61) Liu, J.; Liu, M.; Zhang, Z.; Deng, X.; Zhuang, D. Study on spatial pattern of land-use change in China during 1995-2000. Science in China Series D: Earth Sciences 2003, 46 (4), 373-384.

(62) McGarigal, K.; Cushman, S.; Ene, E. FRAGSTATS, v4; spatial pattern analysis program for categorical and continuous maps. University of Massachusetts; Amherst, MA, 2012.

(63) Tyler, M. W.; Peterson, D. L. Effects of forest policy on landscape pattern of late-seral forest of the Western Olympic Peninsula, Washington. Agric. Ecosvst. Environ. 2004, 101 (2), 289306.

(64) Rempel, R. S.; Kaukinen, D.; Carr, A. P. Patch Analyst and Patch Grid; Ontario Ministry of Natural Resources. Centre for Northern Forest Ecosystem Research, Thunder Bay, Ontario, 2012.

(65) Gao, J.; Li, S. Detecting spatially non-stationary and scaledependent relationships between urban landscape fragmentation and related factors using geographically weighted regression. Appl. Geogr 2011, 31 (1), 292-302.

(66) Demurger, S.; Sachs, J. D.; Woo, W. T.; Bao, S. M.; Chang, G. The relative contributions of location and preferential policies in China's regional development: Being in the right place and having the right incentives. China Econ Rev. 2002, 13 (4), 444-465.

(67) Chasco, C. Geodaspace: a resource for teaching spatial regression models. Rect@ 2013, 4 (SpecialIssue), 119-144.

(68) Elhorst, J. P. Specification and estimation of spatial panel data models. Int. Regional Sci. Rev. 2003, 26 (3), 244-268.

(69) Kelejian, H. H.; Prucha, I. R. Specification and estimation of spatial autoregressive models with autoregressive and heteroskedastic disturbances. I. Econometrics 2010, 157 (1), 53-67.

(70) Deng, J. S.; Wang, K.; Hong, Y.; Qi, J. G. Spatio-temporal dynamics and evolution of land use change and landscape pattern in response to rapid urbanization. Landscape Urban Plan 2009, 92 (3), $187-198$.

(71) Paudel, S.; Yuan, F. Assessing landscape changes and dynamics using patch analysis and GIS modeling. ITC J. 2012, 16, 66-76.

(72) Li, C.; Li, J. X.; Wu, J. G. Quantifying the speed, growth modes, and landscape pattern changes of urbanization: a hierarchical patch dynamics approach. Landscape Ecol 2013, 28 (10), 1875-1888.

(73) Kuang, W.; Liu, J.; Dong, J.; Chi, W.; Zhang, C. The rapid and massive urban and industrial land expansions in China between 1990 and 2010: A CLUD-based analysis of their trajectories, patterns, and drivers. Landscape Urban Plan 2016, 145, 21-33.

(74) Wei, Y.; Zhang, Z. Assessing the fragmentation of construction land in urban areas: An index method and case study in Shunde, China. Land Use Policy 2012, 29 (2), 417-428.

(75) Liu, X. P.; Li, X. A new landscape index for quantifying urban expansion using multi-temporal remotely sensed data. Landscape Ecol. 2010, 25 (5), 671-682.

(76) Liu, X. P.; Ma, L.; Li, X.; Ai, B.; Li, S. Y.; He, Z. J. Simulating urban growth by integrating landscape expansion index (LEI) and cellular automata. Int. I. Geogr. Inf. Sci. 2014, 28 (1), 148-163. 